\title{
Direct Electron Transfer to Cytochrome c Induced by a Conducting Polymer
}

Sara López-Bernabeu ${ }^{1}$, Francisco Huerta ${ }^{2}$, Emilia Morallón ${ }^{1}$ and Francisco Montilla*,1

1 Departamento de Química Física e Instituto Universitario de Materiales de Alicante. Universidad de Alicante. Apdo. de Correos 99, E-03080 Alicante, Spain

${ }^{2}$ Departamento de Ingenieria Textil y Papelera, Universitat Politecnica de Valencia, Plaza Ferrandiz y Carbonell, 1, E-03801 Alcoy, Spain.

* Corresponding author: francisco.montilla@ua.es 


\begin{abstract}
The direct electron transfer (DET) to redox proteins has become a central topic in the development of biotechnological devices. The present work explores the mechanisms of the direct electrochemistry between cytochrome $\mathrm{c}$ and a conducting polymer, PEDOTPSS. This polymer has been electrosynthesized from its monomers in aqueous solution on gold electrodes and its capabilities for DET to cyt $\mathrm{c}$ have been examined by electrochemical and spectroelectrochemical methods. The polymer was electrodeposited with controlled thickness and we determined the electron transfer rate constant for cyt $\mathrm{c}$ oxidation was about 2 orders of magnitude higher than those obtained at conventional electrodes. Spectroelectrochemical measurements allowed to evaluate the redox state of the polymer as a function of the potential and, in addition, the observation of intrinsic cyt c redox activity upon electron transfer from the conducting polymer. During the oxidation process of this protein, lysine residues placed near the heme crevice interact electrostatically with the anionic polyelectrolyte PSS. This interaction favors the orientation of the heme group towards the chains of PEDOT backbone, which is the eventual responsible for the electron transfer to the protein.
\end{abstract}




\section{Introduction}

The direct electron transfer (DET) from conducting materials to redox proteins has been examined extensively for years due to its fundamental interest in biochemistry mechanistic studies ${ }^{1,2}$. Nowadays, this charge transfer process is a central issue in the development of nanobiotechnological devices, such as biosensors for health monitoring or enzymatic fuel cells ${ }^{3-6}$.

Among redox proteins, cytochrome c (cyt c) is probably one of the most extensively explored compound due to its key role in the respiratory chain ${ }^{7-13}$. Cyt $\mathrm{c}$ is a water soluble heme protein, with spherical shape and near $3 \mathrm{~nm}$ in diameter, which has the function of accepting electrons from cyt $\mathrm{c}$ reductase and delivering them to cyt $\mathrm{c}$ oxidase in the mitochondrial inner-membrane ${ }^{14}$. Intensive research has shown it is not easy to achieve DET to cyt $\mathrm{c}$ at solid electrode surfaces, since the redox-active heme centre is wrapped by the peptide chain and protected from the solvent ${ }^{15,16}$. It is known that Cyt $\mathrm{c}$ adsorbs strongly on conventional metal electrodes like $\mathrm{Pt}, \mathrm{Hg}, \mathrm{Au}$ or $\mathrm{Ag}^{17}$ and conformational changes suffered by the protein (unfolding and/or denaturation) lead to slow electrontransfer kinetics ${ }^{18,19}$. This difficulty has been overcome by using electrode modifiers such as metal oxides, advanced carbon materials, DNA or lipid membranes ${ }^{20-26}$. In particular, the modification of surfaces with organic thin films like self-assembled monolayers (SAM), has been extensively used to manipulate the electrode surface, promoting the appropriate orientation of the protein and thus enhancing its electroactivity ${ }^{27-36}$.

Conducting polymers prepared by electrochemical methods constitute a class of organic modifiers that offer high versatility in several biotechnological applications of proteins. These materials have been used as enzyme immobilizers, DNA biosensors, electronic transducers in biosensors or drug delivery systems among others ${ }^{37-39}$. Due to its adaptability and ease of preparation, conducting polymers have been also used as 
promoters of DET to several redox proteins and, particularly, to cyt c. Polyaniline (PANI) is, probably, the most studied synthetic conducting material, but the lack of electrical conductivity observed at neutral $\mathrm{pH}$ hampers its use in biological systems. Self-doped polyanilines could be adopted for this application but due to their low activity for DET reactions, they were mainly used as protein entrappers in combination with carbon materials ${ }^{40-42}$. Similar application can be found for pyrrole and thiophene-based conducting polymers despite they seemed more adequate than PANI since both are electroactive at physiological $\mathrm{pH}$. In most cases, polypyrrole and polythiophene films serve merely as the matrix to embed nanostructures (gold nanoparticles, carbon nanotubes, graphene, etc.) that are employed for DET to proteins in sensor applications ${ }^{43-}$ 46. Little number of fundamental studies based exclusively on conducting polymers (i.e. in the absence of other promoters) can be found in relation to the direct electron transfer to proteins.

Poly(3,4-ethylenedioxythiophene) doped with poly-styrene sulfonate (PEDOT-PSS) is one of the most successful conducting polymers in terms of practical applications. Its ability to form thin and homogeneous films, optical transparency in the visible light region, high electrical conductivity and good physical and chemical stability in air, made this polymer very common in a wide range of applications ${ }^{47}$. PEDOT-PSS can be electrodeposited on suitable electrodes from aqueous solution containing EDOT monomer. The solubility in water of EDOT is rather low but the addition of PSS acting as surfactant and doping agent solves the problem ${ }^{48}$.

The present paper explores the modification of metal electrode with PEDOT-PSS prepared by electrochemical methods from aqueous solutions and its use to the study of the direct electron transfer of cyt c. The combination of vibrational spectroscopy and electrochemistry experiments allow to gain information on the molecular processes 
involved during the doping of PEDOT-PSS. The ability of PEDOT-PSS to induce a proper orientation of the protein for DET was explored by the spectroelectrochemical technique.

\section{Experimental}

Cytochrome c (cyt c) from horse heart (98\%), 3,4-ethylendioxythiophene (EDOT) (97\%), poly(sodium 4-styrenesulfonate) (PSS) and deuterium oxide (99.9 atom \% D) were purchased from Sigma-Aldrich, whereas potassium dihydrogen phosphate and dipotassium hydrogen phosphate were from Merck. All the reagents were of analytical grade. The solutions were prepared with ultrapure water obtained from an Elga Labwater Purelab system $(18.2 \mathrm{M} \Omega \mathrm{cm})$.

The phosphate buffer solution (PBS, $\mathrm{pH} 7$ ) was a mixture $0.15 \mathrm{M} \mathrm{K}_{2} \mathrm{HPO}_{4}+0.10 \mathrm{M}$ $\mathrm{KH}_{2} \mathrm{PO}_{4}$. EDOT electropolymerization was carried out in aqueous medium prepared by dissolving $1.46 \mathrm{~g}$ PSS in $10.0 \mathrm{~mL}$ ultrapure water, $50 \mu \mathrm{L}$ EDOT monomer were then added and the resulting solution was stirred in an ultrasonic bath during 30 minutes. The composition of the final mixture for electropolymerization was $0.15 \%(\mathrm{w} / \mathrm{w})$ PSS and 47 mM EDOT monomer.

Cyclic voltammetry experiments were carried out using a Wenking ST 72 Potentiostat from Bank Elektronik, a wave programmer from EG\&G PARC and an eDAQ-410 digital recorder equipped with eDAQ-EChart data acquisition software. The electrochemical cells were purged by bubbling $\mathrm{N}_{2}$ for $20 \mathrm{~min}$, and the inert atmosphere was maintained during all the experiments. All the potentials were measured against a reversible hydrogen electrode (RHE) immersed in the same electrolyte and are presented in that scale. A 
platinum wire was used as the counter electrode and a $0.080 \mathrm{~cm}^{2}$ polycrystalline gold sphere as the working electrode.

X-ray photoelectron spectroscopy (XPS, K-ALPHA, Thermo Scientific) was used to analyse the sample surface. All spectra were collected using Al-K radiation (1486.6 eV), monochromatized by a twin crystal monochromator, yielding a focused X-ray spot (elliptical in shape with a major axis length of $400 \mu \mathrm{m}$ ) at $3 \mathrm{~mA} \times 12 \mathrm{kV}$. The alpha hemispherical analyser was operated in the constant energy mode with survey scan pass energies of $200 \mathrm{eV}$ to measure the whole energy band and $50 \mathrm{eV}$ in a narrow scan to selectively measure individual elements. XPS data were analysed with Avantage software. A smart background function was used to approximate the experimental backgrounds and surface elemental composition were calculated from backgroundsubtracted peak areas. Charge compensation was achieved with the system flood gun that provides low energy electrons and low energy argon ions from a single source. The experimental curves were adjusted using a combination of Lorentz (30\%) and Gaussian (70\%) functions.

In situ FT-IR spectroscopy was performed in a Nicolet Thermo 5700 spectrometer equipped with a liquid nitrogen-cooled mercury-cadmium telluride, MCT, detector. The three-electrode spectroelectrochemical cell was equipped with a prismatic $\mathrm{CaF}_{2}$ window bevelled at $60^{\circ}$. The working solution was bubbled with Ar flow for $20 \mathrm{~min}$ and the inert atmosphere was maintained during all the experiments. The counter electrode was a gold ring and a reversible hydrogen electrode (RHE) was used as the reference one. The working electrode was a mirror-polished gold disc. In situ FTIR spectra were collected in the external reflection-absorption mode at $8 \mathrm{~cm}^{-1}$ resolution. Typically, 100 to 500 interferograms were processed with OMNIC data acquisition software to obtain both the background and the sample spectrum. 


\section{Results and Discussion}

\subsection{Electrochemical synthesis of PEDOT-PSS}

Fig. 1 shows the electrochemical oxidation of EDOT on a gold substrate in aqueous solution containing PSS.
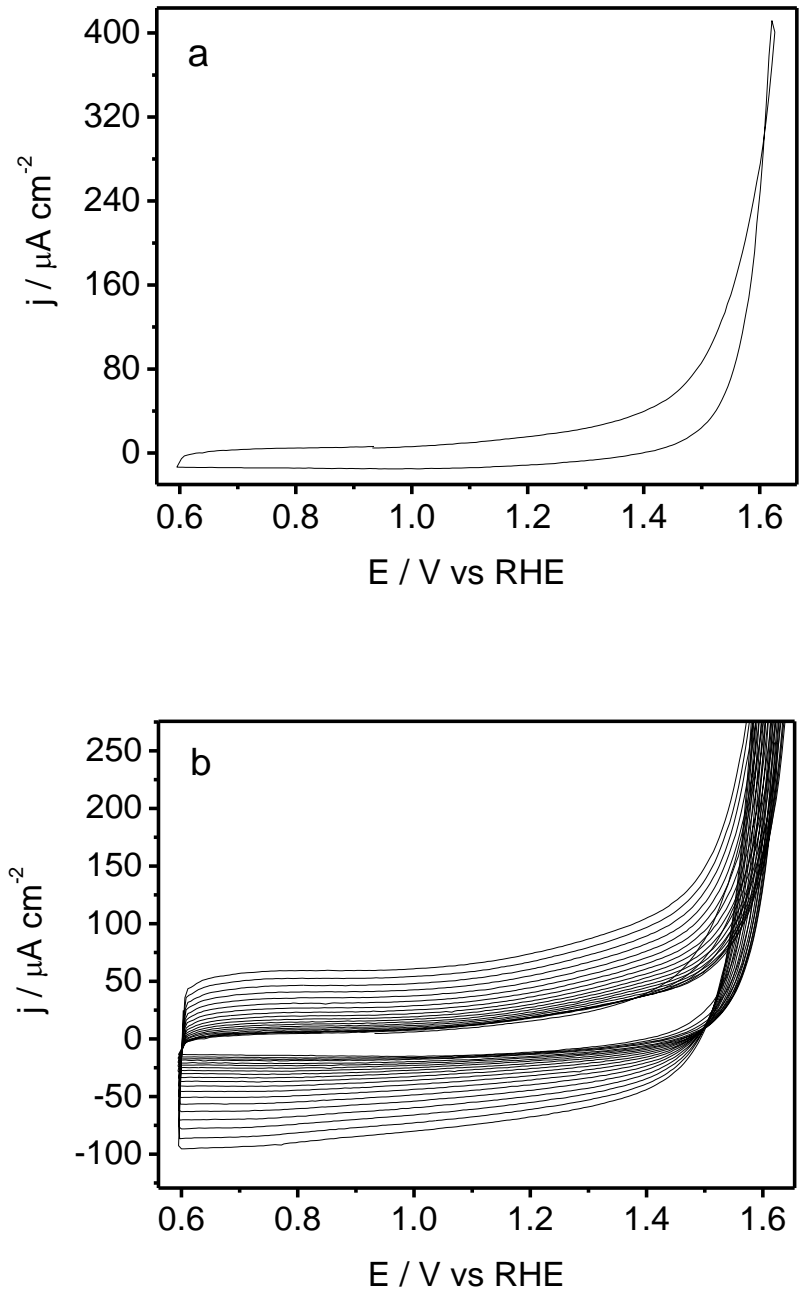

Figure 1: Cyclic voltammograms recorded during the potentiodynamic growth of a PEDOT-PSS film on a gold electrode from an aqueous solution containing $47 \mathrm{mM}$ $\mathrm{EDOT}+0.15 \%$ PSS aqueous solution. Scan rate $100 \mathrm{mV} \mathrm{s}^{-1}$. (a) first cycle; (b) successive potential cycles. 
The first potential cycle is presented in Fig. 1a, where a featureless voltammetric profile is recorded until a potential value above $1.45 \mathrm{~V}$ is reached. This point corresponds to the onset of EDOT monomer oxidation and, consequently, to the formation of PEDOT. The inversion potential was set at $1.6 \mathrm{~V}$ in order to obtain a suitable growth rate of polymeric material. On subsequent potential scans (see Fig. 1b), it is observed the presence of a current plateau in the potential region between $0.6 \mathrm{~V}$ and $1.4 \mathrm{~V}$, showing capacitive character and increasing voltammetric charge. This feature is assigned to the growth of PEDOT-PSS on the electrode surface. The charge of the capacitive current can be related with the mass of PEDOT-PSS deposited on the gold surface. This has been done by taking a double layer capacitance of $67.7 F g^{-1}$ for this material, as it was determined by Bobacka and coworkers ${ }^{49}$. Therefore, in this case, cyclic scanning of the potential provides a unique tool to in situ monitor the amount of deposited polymer.

The chemical composition of the deposited layer was determined by means of XPS spectroscopy. Fig. 2 shows the photoelectronic spectrum of the $S$ p region for a PEDOTPSS film. The presence of two major bands corresponding to different sulphur species with different oxidation states is clearly observed. Both signals can be deconvoluted into two contributions, showing a characteristic separation between the $2 \mathrm{p}_{3 / 2}$ and $2 \mathrm{p}_{1 / 2}$ spinsplit doublets of $1.18 \mathrm{eV}$. The low energy signal, with a S $2 \mathrm{p}_{3 / 2}$ contribution peaking at $163.8 \mathrm{eV}$, is assigned to sulphur atoms located at thiophene rings in EDOT monomers ${ }^{50}$. On the other hand, the $S 2 p_{3 / 2}$ contribution to the higher binding energy signal $(167.9 \mathrm{eV})$ is attributed to sulphur in a higher oxidation state and, consequently, corresponds to those sulfonate groups contained in the PSS dopant anion ${ }^{51}$. The analysis of both S $2 p$ signals shows that the sulfonate/thiophene ratio in electrodeposited PEDOT-PSS films is closed to 3.5 . 


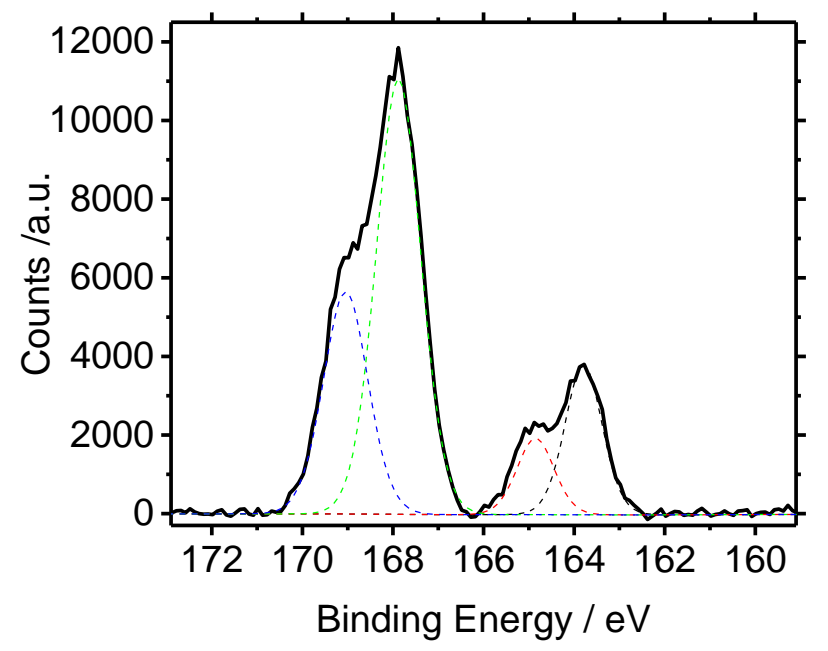

Figure 2. High resolution XPS signal for S 2p obtained from a PEDOT-PSS film electrodeposited on a gold substrate.

\subsection{Electrochemical characterization of the direct electron transfer between cyt c and}

\section{PEDOT-PSS}

It is known that cyt $\mathrm{c}$ molecules in bulk solution do not transfer charge significantly to metal electrodes. In fact, Fig. 3 shows the steady state cyclic voltammogram of a bare gold electrode immersed in $5 \mathrm{mg} \mathrm{mL}^{-1}$ cyt c solution, where no redox features showing electrochemical activity of this macromolecule can be distinguished (dotted line in Fig. 3). On the contrary, a PEDOT-PSS film shows a clear-cut ability to serve as an active substrate for cyt $\mathrm{c}$ oxidation. The oxidation of ferrocytochrome $\mathrm{c}$ to ferricytochrome $\mathrm{c}$ occurs under the anodic peak centred at $0.67 \mathrm{~V}$ and the reduction counter process appears as a cathodic feature peaking at $0.61 \mathrm{~V}$ (see solid line). If no cyt $\mathrm{c}$ is added to the working solution, a PEDOT-PSS film of the same thickness shows only capacitative current in the potential region comprised between $0.4 \mathrm{~V}$ and $1.0 \mathrm{~V}$ (dashed curve). 


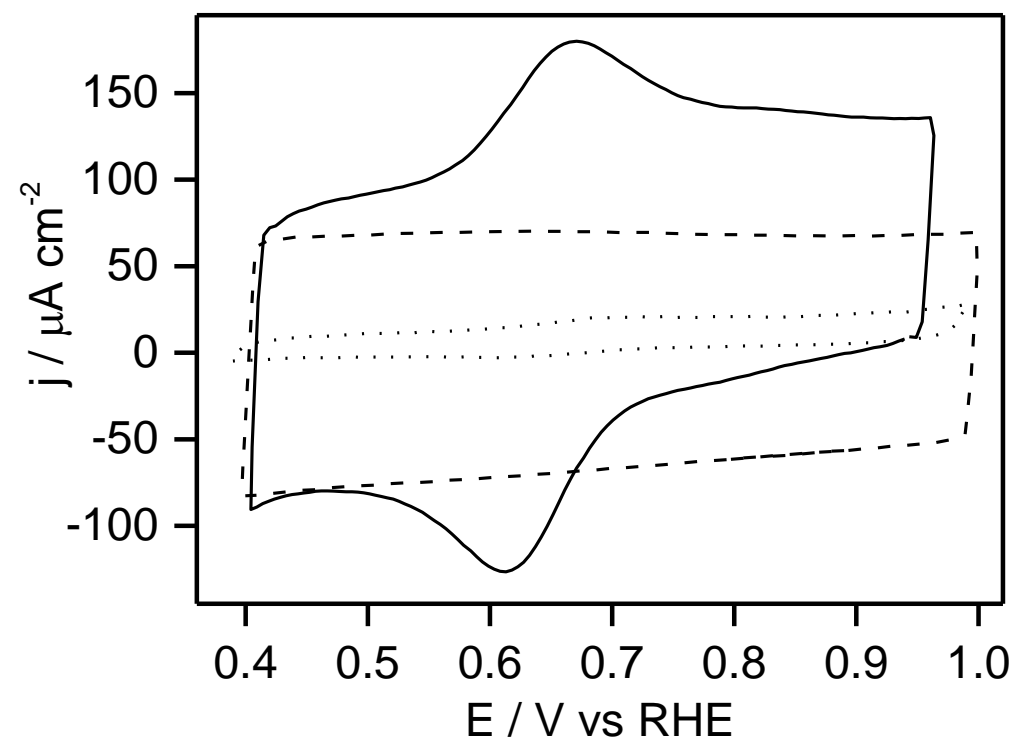

Figure 3. Steady state cyclic voltammograms recorded for bare gold (dotted line) and $0.11 \mu \mathrm{m}$ PEDOT-PSS/gold (solid line) electrodes in PBS solution containing $5 \mathrm{mg} \mathrm{mL}^{-1}$ cyt c. Dashed line is de CV for a $0.11 \mu \mathrm{m}$ layer of PEDOT-PSS on gold in PBS, pH 7, with no cyt c added. Scan rate $100 \mathrm{mV} \mathrm{s}^{-1}$ in all cases.

Once the ability of PEDOT to transfer charge to cyt $\mathrm{c}$ has been established, the effect of polymer thickness on the electrochemical process will be analysed in depth. Fig. 4 shows steady-state cyclic voltammograms recorded in the same $5 \mathrm{mg} \mathrm{mL}^{-1}$ cyt c solution for gold electrodes modified with PEDOT-PSS films of increasing thickness. All the voltammetric curves show the characteristic pair of redox peaks accompanying the reversible electrochemical oxidation of the protein iron centre. Such evidence opens the question of finding out the most suitable PEDOT thickness or, in other words, the deposit showing better electrochemical kinetics. 


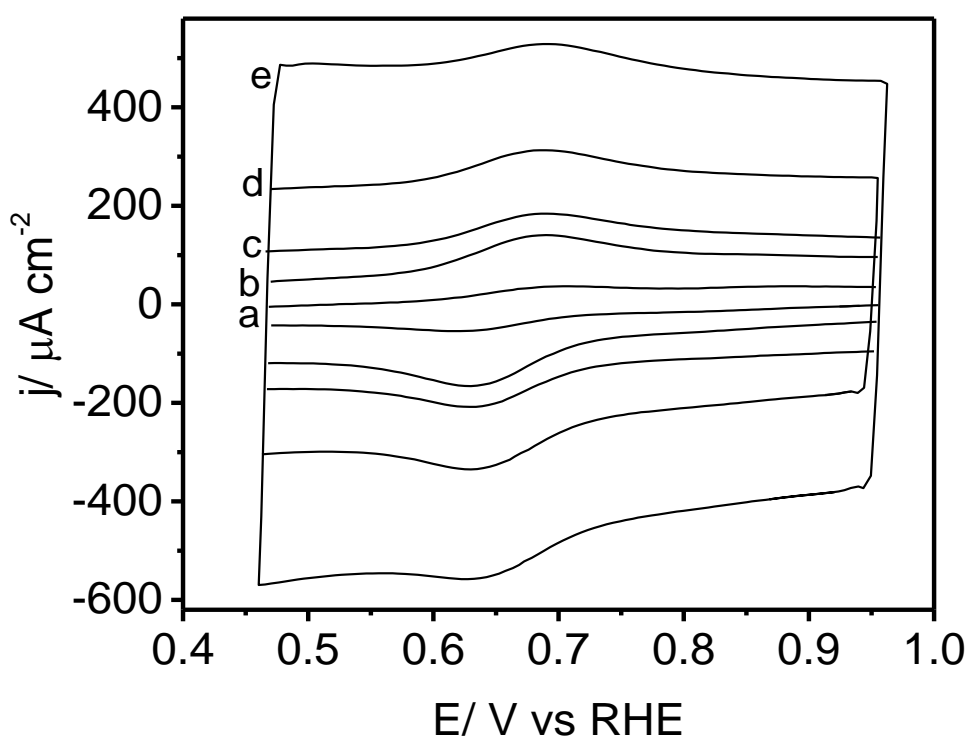

Figure 4. Steady state cyclic voltammograms recorded in PBS containing $5 \mathrm{mg} \mathrm{mL}^{-1}$ cyt c. The electrode was a gold substrate covered with PEDOT films of increasing thickness: (a) 0.02, (b) 0.09, (c) 0.18, (d) 0.36 and (e) $0.71 \mu \mathrm{m}$. Scan rate $100 \mathrm{mV} \mathrm{s}^{-1}$.

To achieve this, an analysis of voltammetric peak currents and peak separations as a function of the polymer thickness was carried out. Fig. 5a shows the peak-to-peak separation of the redox process and, as observed, there is a minor effect of polymer thickness on cyt c electron transfer kinetics. $\Delta E_{p}$ recorded at extremely thin PEDOT-PSS films $(<40 \mathrm{~nm})$ show a marked irreversibility, but peak separation stays between 60 and $65 \mathrm{mV}$ in most cases, which represents a quasireversible process. Consequently, the electrochemical reversibility of the cyt c electron transfer seems not significantly affected when occurring at PEDOT films with thickness between 0.04 and $0.7 \mu \mathrm{m}$. From the results presented in Fig. 5, an average heterogeneous transfer rate constant, $k^{o}$, for the electrochemical reaction can be determined by means of Nicholson's method. ${ }^{52}$ The $k^{o}$ value amounts to $0.049 \mathrm{~cm} \mathrm{~s}^{-1}$, as obtained from the average value of peak separation 
between 0.04 and $0.7 \mu \mathrm{m}\left(\Delta E_{p}=62 \mathrm{mV}\right.$, SD $\left.2 \mathrm{mV}\right)$. This number indicates that the electron transfer reaction is faster through the PEDOT-PSS modified electrode than for other widely used electrodes such as ITO, carbon materials or chemically-modified gold substrates, for which typical values in the order of $10^{-3}-10^{-4} \mathrm{~cm} \mathrm{~s}^{-1}$ are reported ${ }^{24,53-56}$.
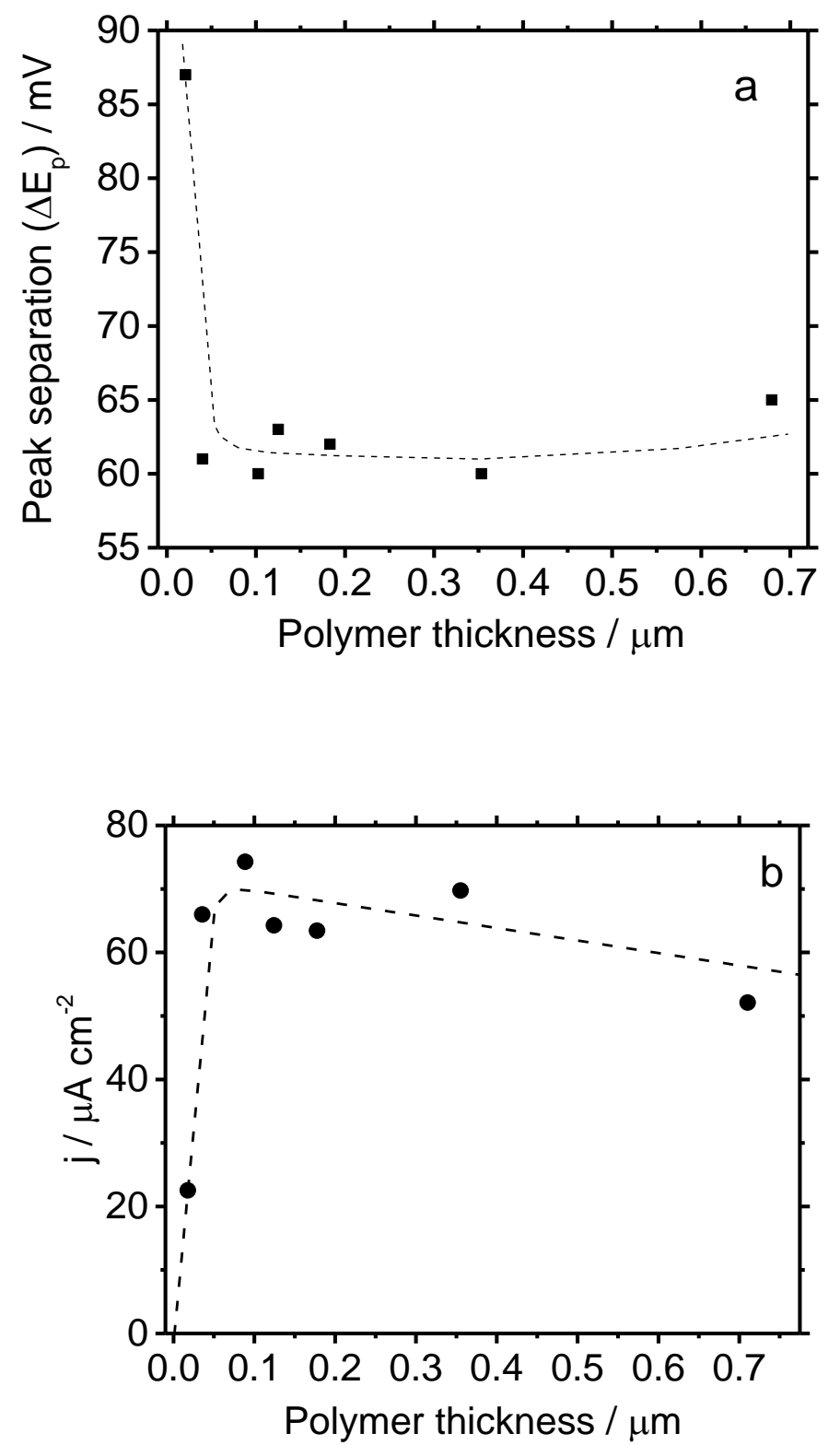

Figure 5. Effect of PEDOT layer thickness on: (a) separation between redox peaks, and (b). cyt c redox anodic peak current density. Working solution: $5 \mathrm{mg} \mathrm{mL}^{-1}$ cyt c in PBS, pH 7. 
The plot in Fig. 5b shows how the recorded current density of the anodic redox peak is almost zero in the absence of deposited polymer but it rises significantly in the presence of thin PEDOT-PSS films. In fact, it seems that the current density decreases for deposits thicker than $0.1 \mu \mathrm{m}$. It is believed that thicker films show a non-uniform vertical conductivity, which could be at the origin of the observed effect. In this context, it is worth mentioning that the existence of a vertical conductivity gradient at PEDOT-PSS inserted within $\mathrm{SiO}_{2}$ matrix was already suggested in previous works ${ }^{48}$. As expected, the redox current involved in the redox process increases proportionally to the concentration of protein in PBS but, remarkably, the measured current does not depend on the amount of electrodeposited polymer (see figure S1 of the supporting information).

\subsection{In situ FTIR study on the direct electron transfer between cyt c and PEDOT}

Several conducting polymers such as those obtained from aniline, pyrrole and their monomer derivatives show interesting redox properties that can be characterized at molecular level by the so-called electrochemical in situ spectroscopies. Among them, in situ FTIR spectroscopy constitutes a unique tool to monitor the effect of the applied potential on the vibrational features of polymer redox active centres. Chemically reversible redox transitions in conducting polymers usually involve interconversion of functional groups and, consequently, significant absorption changes in the infrared region of the electromagnetic spectra. PEDOT-PSS is, nevertheless, one of the widely used, less studied conducting polymers by in situ FTIR spectroscopy. Just a few contributions devoted to the analysis of the effect of the applied potential on the absorption spectrum

can be found in the literature ${ }^{57-59}$. In situ FTIR spectroscopy will be used in the present 
work to gain insight on fundamental aspects of the direct electron transfer occurring between cyt $\mathrm{c}$ and PEDOT-PSS. Accordingly, it is firstly required a vibrational characterization of PEDOT-PSS redox transitions in the absence of cyt c. Fig. 6a shows a set of in situ FTIR spectra obtained in PBS for a gold electrode covered with an electrodeposited $0.04 \mu \mathrm{m}$ PEDOT-PSS layer. The modified electrode was immersed in the spectroelectrochemical cell containing PBS test solution at $0.2 \mathrm{~V}$ and then pressed against the $\mathrm{CaF}_{2}$ window. A set of 100 interferograms was acquired at this potential to be used as the reference spectrum and, then, the potential was scanned sequentially up to 1.3V. Sets of 100 sample interferograms were collected every $100 \mathrm{mV}$ step and referred to the spectrum at $0.2 \mathrm{~V}$. The resulting differential spectra are depicted in Fig. 6a. There, each single spectrum represents changes in vibrational modes occurring at increasing sample potentials relative to the unique reference spectrum. In this way, positive-going (upward) bands can be assigned to the weakening or extinction of vibrational modes at the sample potential while negative-going (downward) bands to their strengthening. At this point, it should be noted that PSS contained within PEDOT matrix is not redox-active and, consequently, it is expected that its vibrational modes will show zero or negligible intensity in the normalized differential FTIR spectra.

The first spectrum in Fig. 6a was obtained at a sample potential of $0.6 \mathrm{~V}$. There, three obvious negative-going bands are detected at 1535,1420 and $1250 \mathrm{~cm}^{-1}$, in addition to two positive-going bands at 1470 and $1365 \mathrm{~cm}^{-1}$. The band at $1535 \mathrm{~cm}^{-1}$ can be assigned to the antisymmetric $\mathrm{C}-\mathrm{C}$ stretching mode within oxidized thiophene rings ${ }^{60-63}$. Fig. $6 \mathrm{~b}$ shows how the integrated band intensity of this feature increases almost linearly at increasing potentials. From this behaviour, it is derived that the electrochemical injection of positive charge within the polymer backbone results in a significant and gradual activation of vibrational modes coming from oxidized (polaronic) structures of the 
PEDOT-PSS. Since there is no degradation of the polymer within the potential window employed in the experiment, the almost linear trend replicates the growing oxidative doping level of the deposited material. Furthermore, the intensity stabilization from 1.2 $\mathrm{V}$ means that the complete oxidation of the polymer has been achieved at this potential and overoxidation of the polymer structure could occur beyond such limit.

Table 1. Proposed assignments for the in situ FTIR bands of reduced and oxidized forms of PEDOT-PSS

\begin{tabular}{|c|c|c|c|}
\hline PEDOT Structure & Frequency/cm-1 & Assignment & Refs. \\
\hline \multicolumn{4}{|l|}{ Reduced } \\
\hline & 1470 & Aromatic $\mathrm{C}-\mathrm{C}$ ring str. & $59,62,64,65$ \\
\hline & 1365 & Aromatic $\mathrm{C}-\mathrm{C}$ ring str. & $60,61,64,65$ \\
\hline \multicolumn{4}{|l|}{ Oxidized } \\
\hline & 1535 & $\mathrm{C}_{\alpha}-\mathrm{C}_{\beta}$ antisymm str. & $60-63,66$ \\
\hline & 1420 & $\mathrm{C}_{\alpha}-\mathrm{C}_{\beta}$ symm str. & $60,62,64,66$ \\
\hline & 1250 & $\mathrm{C}_{\alpha}=\mathrm{C}_{\alpha}$ symm str. & 61,66 \\
\hline
\end{tabular}

On the contrary, the intensity of the two positive-going bands (which are related to a pair of ring-stretching vibrations of thiophene, typical of five-membered heterocycle compounds ${ }^{65}$ remains almost constant upon positive charge injection. This result strongly suggests that the two vibrational modes coming from the reduced state of the polymeric 
material vanish at the early stages of electrochemical oxidation and, consequently, it seems that a sudden loss of the aromatic character of thiophene rings takes place at very low potentials, above $0.2 \mathrm{~V}$.

Changes in band frequency at increasing potentials have been also depicted for the 1535 $\mathrm{cm}^{-1}$ absorption in Fig. 6c. The clear frequency shift observed, with a tuning rate close to $30 \mathrm{~cm}^{-1} \mathrm{~V}^{-1}$, resembles an electrochemical Stark effect ${ }^{67}$. It is known that most thiophenebased conjugated polymers, including also EDOT-based materials, present IR bands whose positions are almost independent on the applied potential. In some particular cases, frequency shifts at increasing doping levels were found, but always associated to specific families of thiophene derivatives ${ }^{68-70}$. No clear explanation of this phenomenon has been offered in the literature to date, although it is believed that electronic transitions between different charged moieties upon oxidation (specifically polaron to bipolaron transitions) could be at the origin of the observed energy shift. Along with the antisymmetric C-C stretching in oxidized EDOT units, the parent symmetric vibration appears as a negative absorption peaking at $1420 \mathrm{~cm}^{-1}$ in the spectra of Fig. 6a. Finally, the low frequency feature at $1250 \mathrm{~cm}^{-1}$ can be attributed to an inter-ring $\mathrm{C}-\mathrm{C}$ stretching vibration ${ }^{61,63}$. All these assignments have been summarized in Table 1. Vibrational modes coming from $\mathrm{C}-$ $\mathrm{S}$ bonds in thiophene rings appear at frequencies below those of the $\mathrm{CaF}_{2}$ window cut-off and, consequently, are undetectable in our experiments. 


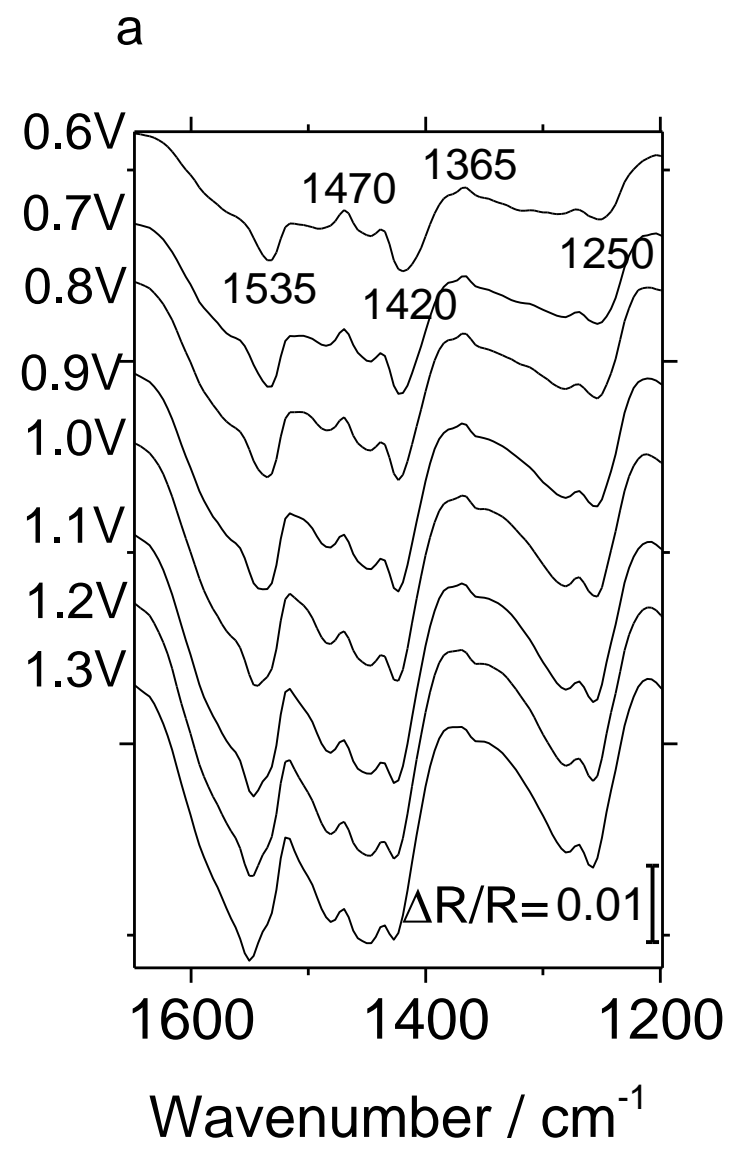

a
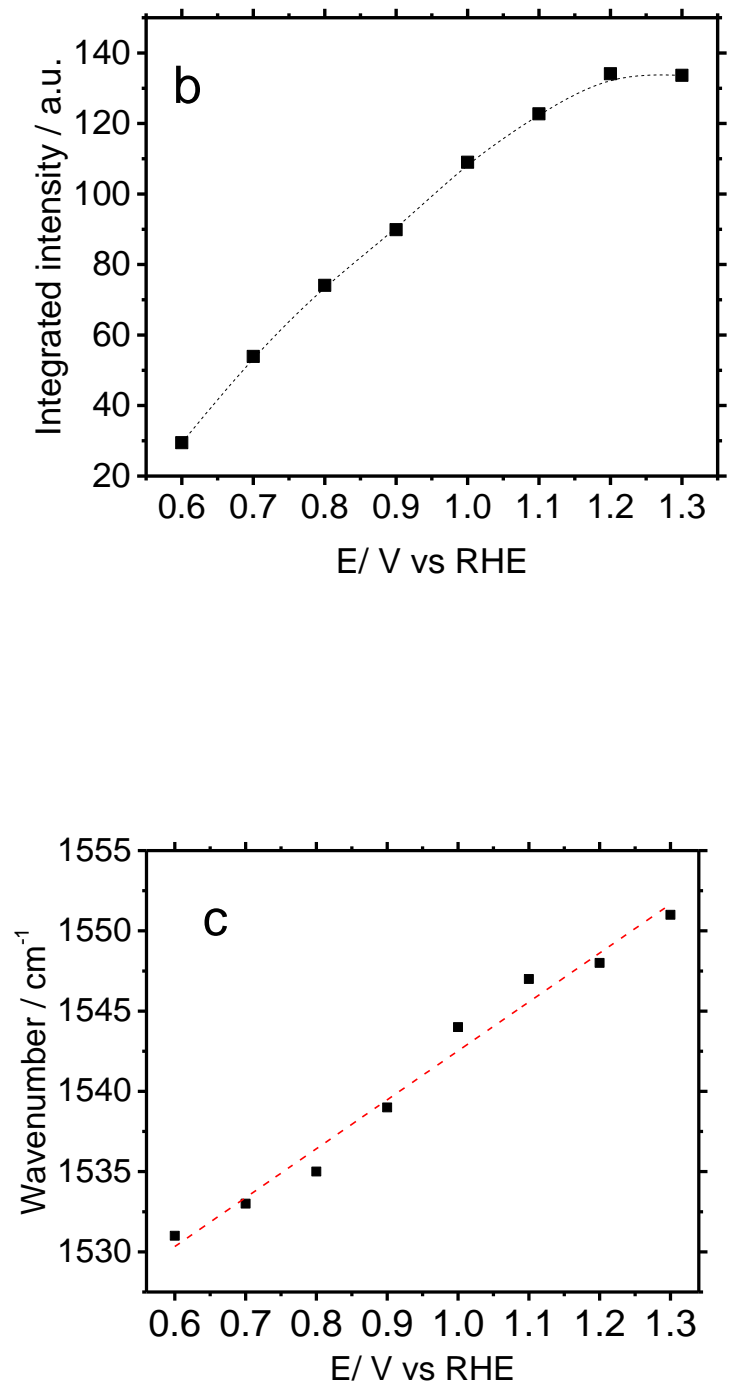

Figure 6. (a) In situ FTIR spectra collected for a thin $(0.04 \mu \mathrm{m})$ deposit of PEDOT on a gold electrode in PBS. Reference spectrum obtained at $0.2 \mathrm{~V} .100$ interferograms at each potential. (b) . Integrated intensity of the $\mathrm{C}_{\alpha}-\mathrm{C}_{\beta}$ antisymmetric stretching against the applied potential. (c) Dependence of the $\mathrm{C}_{\alpha}-\mathrm{C}_{\beta}$ antisymmetric stretching frequency on the applied potential

Once the assignments of the main in situ infrared features have been carried out, the question of how the electron transfer between PEDOT-PSS and cyt c modifies the recorded spectra can be addressed. The spectroelectrochemical response of a PEDOT- 
PSS layer was tested in working solutions containing either PBS (Fig. 7a) or cyt c in PBS (Fig. 7b). In order to increase the signal-to-noise ratio, reference $(0.5 \mathrm{~V})$ and sample $(0.7$ V) potentials were adjusted around the cyt c redox transition and five potential steps between reference and sample potentials were carried out. The 500-interferogram resulting spectra were co-added in order to obtain a unique computed spectrum with enhanced quality in each working solution.
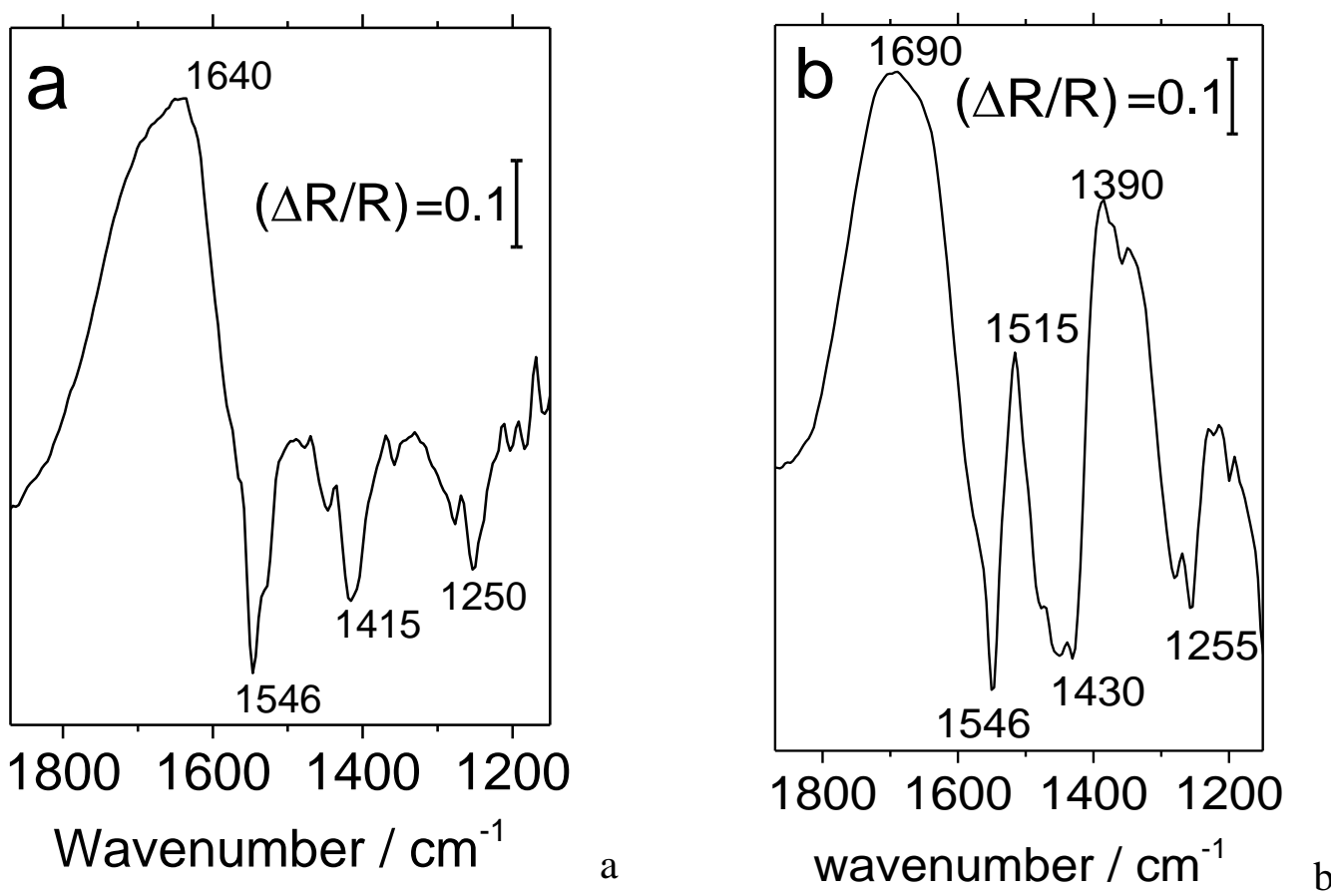

Figure 7. (a) In situ FTIR spectra recorded in PBS for a $0.04 \mu \mathrm{m}$ PEDOT layer deposited on gold. (b) In situ FTIR spectra for a $0.04 \mu \mathrm{m}$ PEDOT deposit in PBS containing $1 \mathrm{mg} \mathrm{mL}^{-1}$ cyt c. Reference: 0.5 V. Sample: 0.7 V. 500 interferograms at each potential.

It can be observed that both spectra are dominated by bands assigned to the redox transitions of the conjugated polymer backbone, in addition to a strong positive band at around $1640 \mathrm{~cm}^{-1}$ coming from the unbalanced $\mathrm{O}-\mathrm{H}$ bending of water molecules and 
associated to the swell-shrink process of PEDOT. It is also worth noting in the spectrum of Fig. 7a that positive features vanish at 1365 and $1470 \mathrm{~cm}^{-1}$ (see Fig. 6a for comparison). This is because the reference spectrum was acquired here at a higher potential $(0.5 \mathrm{~V}$ instead of $0.2 \mathrm{~V}$ ). The aromatic character of thiophene rings was already lost at $0.5 \mathrm{~V}$ and, as a result, only negative-going bands can be observed, since they simply show intensification of the oxidation process at $0.7 \mathrm{~V}$ with respect to $0.5 \mathrm{~V}$. Therefore, it is derived that positive bands at 1515 and $1390 \mathrm{~cm}^{-1}$ in Fig. $7 \mathrm{~b}$ come unambiguously from the reduced state of cyt $\mathrm{c}$ and not from PEDOT-PSS. The former feature is clearly identified as the amide II band ${ }^{71}$ and the latter integrates the amide III region ${ }^{72}$. On the other hand, the negative band at around $1430 \mathrm{~cm}^{-1}$ is overlapped with the PEDOT $\mathrm{C}_{\alpha}-\mathrm{C}_{\beta}$ symmetric stretching and it can be attributed to the intensification of the $\mathrm{C}-\mathrm{H}$ bending at aminoacid side chains occurring upon oxidation ${ }^{32,71,72}$. Another major feature in the spectrum of Fig. 7b involves the amide I infrared region, between $1600-1700 \mathrm{~cm}^{-1}$, which is modulated by the secondary structure of the protein and is really distorted by the $\mathrm{H}_{2} \mathrm{O}$ bending vibration.

To clarify cyt $\mathrm{c}$ infrared transitions appearing in this spectral region, additional experiments were performed using deuterated water as the solvent. In these experiments, the unbalanced $\mathrm{D}_{2} \mathrm{O}$ absorption due to polymer swelling may disturb the frequency region at around $1200 \mathrm{~cm}^{-1}$. Fig. 8 shows a set of spectra for PEDOT-PSS modified electrodes acquired at sample potentials of $0.7 \mathrm{~V}$ in $\mathrm{PBS} / \mathrm{D}_{2} \mathrm{O}$ solutions, either in the absence or in the presence of cyt c. 

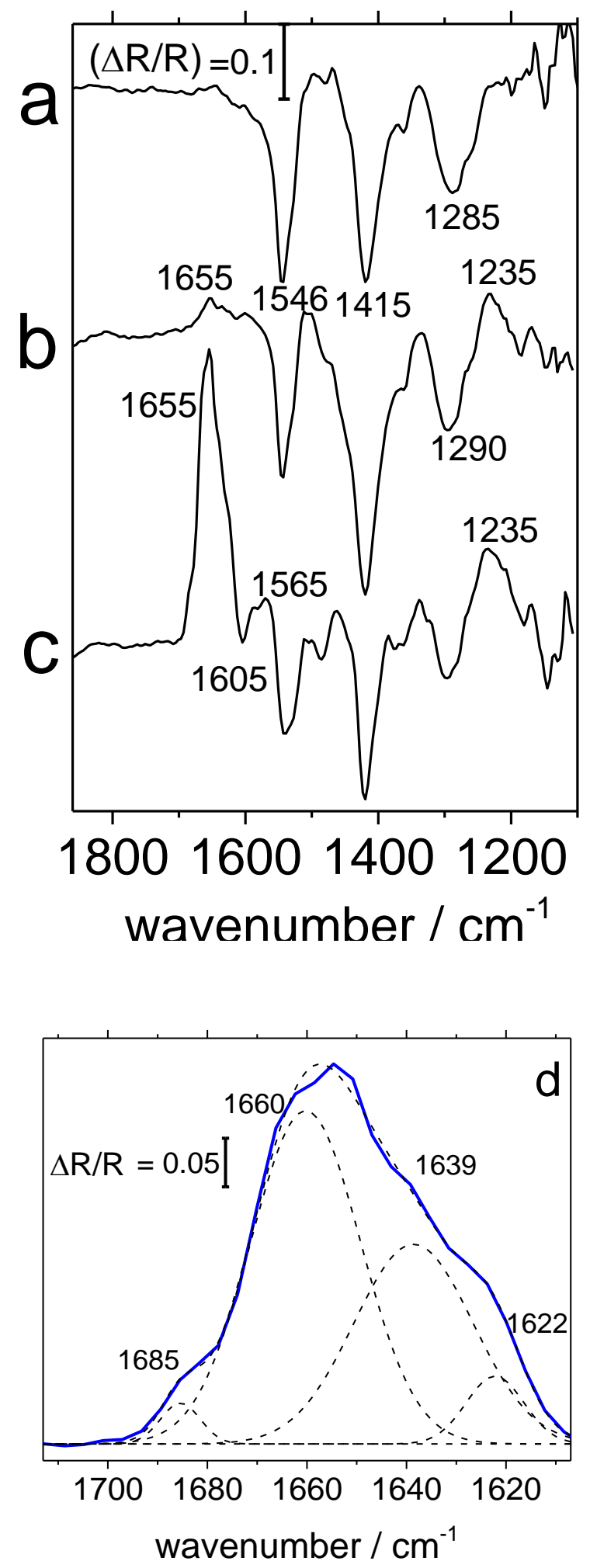

Figure 8. In situ FTIR spectra collected for a $0.04 \mu \mathrm{m}$ PEDOT layer in: (a) $\mathrm{PBS} / \mathrm{D}_{2} \mathrm{O}$ solution; (b) $1 \mathrm{mg} \mathrm{mL}^{-1}$ cyt c in $\mathrm{PBS} / \mathrm{D}_{2} \mathrm{O}$ solution; (c) $3 \mathrm{mg} \mathrm{mL} \mathrm{m}^{-1}$ cyt c in $\mathrm{PBS} / \mathrm{D}_{2} \mathrm{O}$ solution. Sample 0.7 V. Reference 0.5 V. 500 interferograms at each potential. (d) Deconvolution of the amide I band from spectrum c. 
In addition to the IR absorptions assigned to polymer vibrational transitions, spectra collected in the presence of protein (Fig. 8b and 8c) show negative bands at $1605 \mathrm{~cm}^{-1}$ coming from the $v_{37}$ stretching vibration of the heme group and positive bands at 1565 $\mathrm{cm}^{-1}$. This latter feature is assigned to the complex amide II absorption which, in the present case, appears interfered by PEDOT vibrational bands. In spite of this, the key feature for the two spectra collected in the presence of cyt $\mathrm{c}$ is the appearance of a clearcut, positive amide I band centred at $1655 \mathrm{~cm}^{-1}$. As shown in Fig. 8d, this multiple absorption results from the combination of several $\mathrm{CO}, \mathrm{CN}$ and $\mathrm{CCN}$ vibrational transitions coming from the oxidized state of the protein ${ }^{73}$, namely type III $\beta$-turn at 1685 $\mathrm{cm}^{-1}$, type II $\beta$-turn and $\alpha$-helix at $1660 \mathrm{~cm}^{-1}$ and extended $\beta$-strand at $1639 \mathrm{~cm}^{-1}$. A further contribution at $1622 \mathrm{~cm}^{-1}$ is usually assigned to side chain interactions not associated with the secondary structure of cyt $c^{31,34,74,75}$.

The relative intensity between type III and type II $\beta$-turn infrared absorptions has been used by Ataka and Heberle to reveal the orientation of cyt $\mathrm{c}$ during the redox transfer to electrodes modified with SAMs ${ }^{72}$. It was established that hydrophobic SAMs favoured the approach of cyt $\mathrm{c}$ through the type III $\beta$-turn, while more hydrophilic (OH-terminated) SAMs tend to face type II $\beta$-turns toward the electrode surface. The pre-eminence of the latter band in Fig. 8d strongly suggests that PEDOT-PSS behaves as a hydrophilic SAM and favours the approach of the heme group in an angle close to the surface normal. Such an orientation promotes the direct electron transfer between cyt $\mathrm{c}$ and the gold electrode modified with PEDOT.

On the other hand, it is known that cyt $\mathrm{c}$ does not undergo significant conformational changes when switched from the oxidized to the reduced state. Consequently, differential bands observed in the infrared spectra of Fig. 8 should be attributed mainly to changes in 
the orientation of cyt $\mathrm{c}$ on the electrode surface, which are induced externally through the reversible electrochemical oxidation-reduction process. In an ideal case, applying higher potentials to the electrode would result in the generation of a larger number of polaronic moieties along hyper-conjugated PEDOT-PSS chains. However, due to some structural heterogeneity shown by conducting polymers, injected charge appears usually at more localized polymer fragments ${ }^{76}$. Changes in protein orientation (perceived in the form of a combined positive band at $1655 \mathrm{~cm}^{-1}$ ) are therefore limited to the interaction with PEDOT in the immediacy of those active (oxidized) polymer centres. Obviously, those orientation changes can be detected because of the successful charge transfer to cyt c. On the basis of horse cyt c crystal structure (entry 1HRC of Protein Data Bank, PBD), the most probable orientation of the protein with respect to the electrode surface during the electron transfer seems that one presented in Fig. 9. 

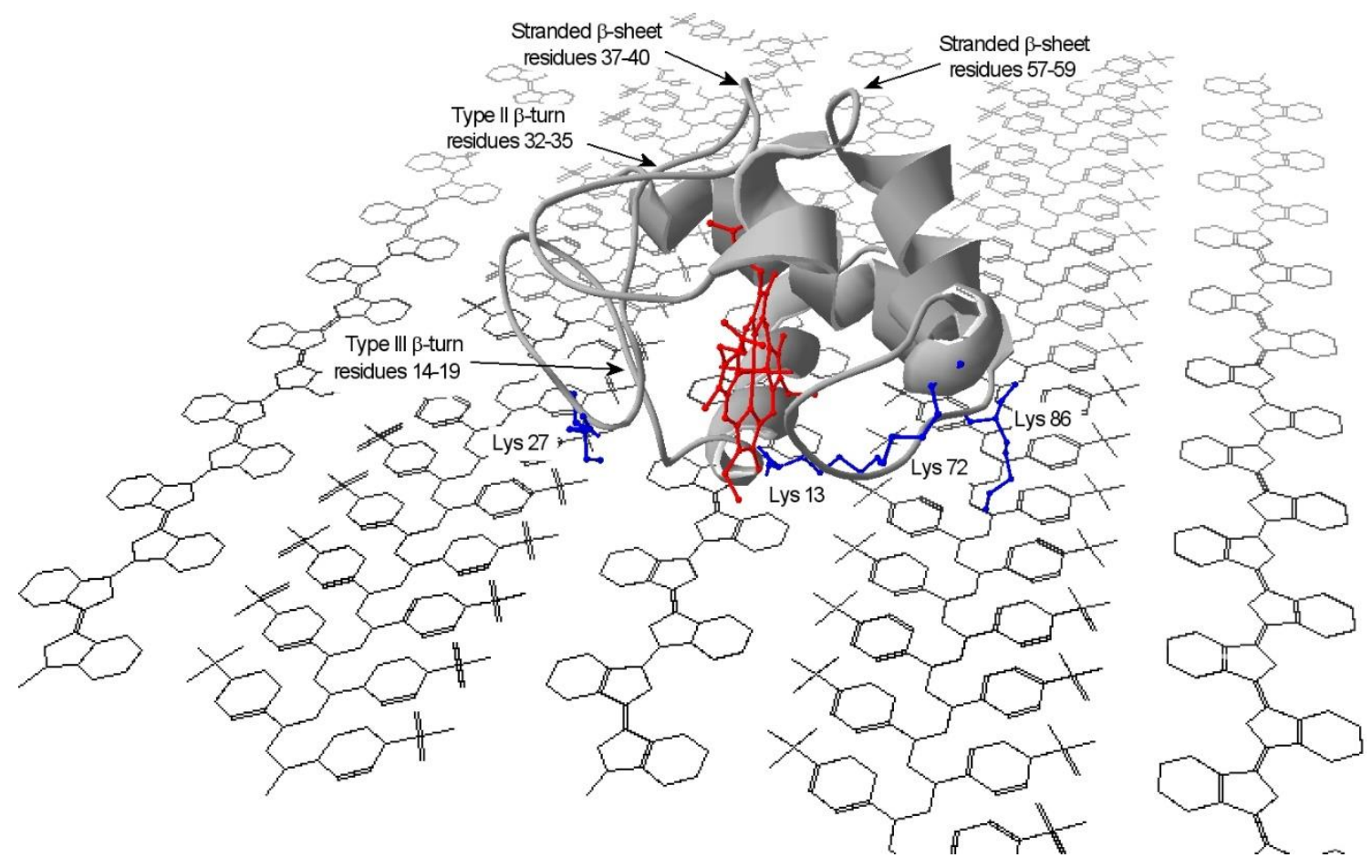

Figure 9. Preferred orientation of cyt c during the electron transfer to a PEDOT layer, as deduced from the combination of crystal structure data and in situ FTIR results. Lys

13, 27, 72 and 86 residues interacting with negatively-charged PSS chains are represented in blue colour. The electro-active heme group, which interacts with PEDOT rings, is represented in red colour. Cyt c structure created by Swiss PDB Viewer 4.1.0 with crystallographic data taken from the Protein Data Bank (PDB entry 1HRC).

Several authors have shown that positively charged residues located at the surface of the cyt c protein, mainly Lys residues, play a major role in the electron transfer process. Those specific protein positions can operate as binding sites that facilitate the electron transfer to partners like cytochrome c oxidase, for which lysine residues $8,13,27,72,79$ and 86 participate in binding, while the remainder lysine centres are not essential for ET. ${ }^{72,77}$

The arrangement proposed in Fig. 9 explains the higher intensity shown by type II $\beta$-turn (residues 32-38) and short stranded $\beta$-sheet (comprising residues 37-40 and 57-59) in the deconvoluted spectra of amide I band. The presence of ionizable groups in His 33, Arg 38 and Lys 39 provides a net positive charge in this protein segment at $\mathrm{pH} 7^{78,79}$ and the 
electrochemical injection of positive charge through the PEDOT backbone could induce additional electrostatic repulsions pulling the segment away from the conducting polymer interface. This effect is detected as a vanishing of the corresponding vibrational modes in the FTIR spectrum of Fig. 8a. On the other hand, it is remarkable the absence of differential infrared bands coming from type III $\beta$-turn (residues 14-19 and 67-70). Such a behaviour reveals that these protein sites remain unmodified upon oxidation and, probably, they are preferred positions for the protein to interact with the conducting polymer. As shown in Fig. 9, the proposed orientation favours the approach of cyt $\mathrm{c}$ to the surface through positively-charged Lys 13, 27, 72 and 86, which seem active residues facilitating the electron transfer from the conducting polymer to the heme group. The interaction of positive Lys residues with the polymer substrate seems favoured by the excess of dopant PSS anions relative to EDOT monomers (ratio close to 4:1, as deduced from XPS data in Fig. 2). In addition, the alignment proposed in Fig. 9 agrees with that reported previously for cyt $\mathrm{c}$ adsorbed on bare gold electrodes ${ }^{77}$. It was demonstrated that this particular configuration hampers the direct electron transfer to cyt $\mathrm{c}$ due to the suppressed rotation of the adsorbed protein. Since, in the present case, the electron transfer takes place from a PEDOT-PSS layer under similar protein alignment, the rotation of cyt c should be not confined after its interaction with this particular conducting substrate.

\section{Conclusions}

We explored the direct electrochemistry of cytochrome c promoted by the conducting polymer PEDOT-PSS. This material was synthesized from aqueous solution and retains its conductive state at physiological $\mathrm{pH}$. It provides several advantages over conventional chemical modifiers (such as SAM films or metallic oxides): PEDOT-PSS is straightforward to synthesize, it can be deposited on any conducting substrate and its 
properties, like morphology or thickness, are easily tunable. We demonstrated electrodes modified with PEDOT-PSS are able to bring charge to cyt $\mathrm{c}$ in solution. The electron transfer rate is about two orders of magnitude higher than those obtained with either conventional or SAM-modified electrodes.

The redox state of the polymer was monitored by in situ FTIR spectroscopy. The injection of positively charged polaronic species produces quinoid domains in the PEDOT backbone. The doped (and therefore conducting) polymer state extends over a wider potential window $(0.2-1.2 \mathrm{~V})$ than that required to induce redox transformations in cyt $\mathrm{c}$ $(0.5-0.9 \mathrm{~V})$

PEDOT-PSS presents IR-active vibrational modes interfering with those associated to intrinsic cyt c redox processes. Under suitable experimental conditions, it was possible to remove vibrational interferences on the amide I band of cyt c. During the oxidation, lysine residues involved in the cyt c coupling processes with their cognate partners (i.e. Lys 13, 27, 72 and 86) interact electrostatically with PSS polyelectrolyte, the anionic dopant. This kind of interaction favors the orifice in the crevice containing the heme group to be oriented towards electroactive PEDOT chains, thus facilitating the electron transfer.

\section{Supporting Information}

The electrochemical response of cyt $\mathrm{c}$ with different PEDOT-modified electrodes (thickness ranging $0.04-0.70 \mu \mathrm{m})$ using several protein concentrations $\left(1,2,5,10 \mathrm{mg} \mathrm{mL}^{-}\right.$ ${ }^{1}$ in PBS) is presented in the Supporting Information.

\section{Acknowledgments}

We gratefully acknowledge financial support from the Spanish Ministerio de Economía y Competitividad and FEDER funds (MAT2013-42007-P and MAT2016-76595-R) and the Generalitat Valenciana (PROMETO2013/038). 


\section{References}

(1) Armstrong, F. A.; Hill, A. O.; Walton, N. J. Direct Electrochemistry of Redox Proteins. Acc. Chem. Res. 1988, 21, 407-413.

(2) Leger, C.; Bertrand, P. Direct Electrochemistry of Redox Enzymes as a Tool for Mechanistic Studies. Chem. Rev. 2008, 108, 2379-2438.

(3) Katz, E.; Willner, I. Integrated Nanoparticle-Biomolecule Hybrid Systems: Synthesis, Properties, and Applications. Angew. Chemie - Int. Ed. 2004, 43 (45), $6042-6108$.

(4) Bullen, R. A.; Arnot, T. C.; Lakeman, J. B.; Walsh, F. C. Biofuel Cells and Their Development. Biosens. Bioelectron. 2006, 21 (11), 2015-2045.

(5) Leech, D.; Kavanagh, P.; Schuhmann, W. Enzymatic Fuel Cells: Recent Progress. Electrochim. Acta 2012, 84, 223-234.

(6) Gorton, L.; Lindgren, A.; Larsson, T.; Munteanu, F. D.; Ruzgas, T.; Gazaryan, I. Direct Electron Transfer between Heme-Containing Enzymes and Electrodes as Basis for Third Generation Biosensors. Anal. Chim. Acta 1999, 400 (1-3), 91-108.

(7) Armstrong, F. A.; Wilson, G. S. Recent Developments in Faradaic Bioelectrochemistry. Electrochim. Acta 2000, 45 (15-16), 2623-2645.

(8) Kim, M. C.; Song, K. H.; Park, S. J. Isothermal Capacitance Transient Spectroscopy Study on Trap Levels in Polycrystalline Sno2 Ceramics. J. Mater. Res. 1993, 8 (6), 1368-1372.

(9) Collinson, M.; Bowden, E. F. Chronoabsorptometric Determination of AdsorptionIsotherms for Cytochrome-C on Tin Oxide Electrodes. Langmuir 1992, 8 (10), $2552-2559$. 
(10) Bowden, E. F.; Hawkridge, F. M.; Blount, H. N. Interfacial Electrochemistry of Cytochrome c at Tin Oxide, Indium Oxide, Gold, and Platinum Electrodes. $J$. Electroanal. Chem. Interfacial Electrochem. 1984, 161 (2), 355-376.

(11) Sagara, T.; Niwa, K.; Sone, A.; Hinnan, C.; Niki, K. Redox Reaction Mechanism of Cytochrome c at Modified Gold Electrodes. Langmuir 1990, 6 (2), 254.

(12) Eddowes, M. J.; Hill, H. A. Electrochemistry of Horse Heart Cytochrome c. J. Am. Chem. Soc. 1979, 101, 4461-4464.

(13) Mines, G. A.; Pascher, T.; Lee, S. C.; Winkler, J. R.; Gray, H. B. Cytochrome c Folding Triggered by Electron Transfer. Chem. Biol. 1996, 3 (6), 491-497.

(14) Wang, L.; Waldeck, D. H. Denaturation of Cytochrome c and Its Peroxidase Activity When Immobilized on SAM Films. J. Phys. Chem. C 2008, 112 (5), 13511356.

(15) Chen, X.; Long, H.-Y.; Wu, W.-L.; Yang, Z.-S. Direct Electrochemical Behavior of Cytochrome c on Sodium Dodecyl Sulfate Modified Electrode and Its Application to Nitric Oxide Biosensor. Thin Solid Films 2009, 517 (8), 2787-2791.

(16) Zhou, Y.; Zhi, J.; Zou, Y.; Zhang, W.; Lee, S.-T. Direct Electrochemistry and Electrocatalytic Activity of Cytochrome c Covalently Immobilized on a BoronDoped Nanocrystalline Diamond Electrode. Anal. Chem. 2008, 80 (11), 41414146.

(17) Wang, L.; Wang, E. Direct Electron Transfer between Cytochrome c and a Gold Nanoparticles Modified Electrode. Electrochem. commun. 2004, 6 (1), 49-54.

(18) Hinnen, C.; Parsons, R.; Niki, K. Electrochemical and Spectroreflectance Studies of the Adsorbed Horse Heart Cytochrome c and Cytochrome c3 from D. Vulgaris, 
Miyazaki Strain, at Gold Electrode. J. Electroanal. Chem. Interfacial Electrochem. 1983, $147(1-2), 329-337$.

(19) Reed, D. E.; Hawkridge, F. M. Direct Electron Transfer Reactions of Cytochrome c at Silver Electrodes. Anal. Chem. 1987, 59 (3), 2334-2339.

(20) Yin, Y.; Wu, P.; Lü, Y.; Du, P.; Shi, Y.; Cai, C. Immobilization and Direct Electrochemistry of Cytochrome c at a Single-Walled Carbon Nanotube-Modified Electrode. J. Solid State Electrochem. 2007, 11 (3), 390-397.

(21) Zhu, L.; Sun, D.; Lu, T.; Cai, C.; Liu, C.; Xing, W. Direct Electrochemistry Behavior of Cytochrome c on Silicon Dioxide Nanoparticles-Modified Electrode. Sci. China Ser. B Chem. 2007, 50 (3), 304-307.

(22) Zhao, G.-C.; Yin, Z.-Z.; Zhang, L.; Wei, X.-W. Direct Electrochemistry of Cytochrome c on a Multi-Walled Carbon Nanotubes Modified Electrode and Its Electrocatalytic Activity for the Reduction of $\mathrm{H} 2 \mathrm{O} 2$. Electrochem. commun. 2005, $7(3), 256-260$.

(23) Liu, H. H.; Lu, J. L.; Zhang, M.; Pang, D. W.; Abruña, H. D. Direct Electrochemistry of Cytochrome c Surface-Confined on DNA-Modified Gold Electrodes. J. Electroanal. Chem. 2003, 544 (SUPPL.), 93-100.

(24) Yoon, J. H.; Lee, K. S.; Yang, J.; Won, M. S.; Shim, Y. B. Electron Transfer Kinetics and Morphology of Cytochrome $\mathrm{c}$ at the Biomimetic Phospholipid Layers. J. Electroanal. Chem. 2010, 644 (1), 36-43.

(25) Koposova, E.; Shumilova, G.; Ermolenko, Y.; Kisner, A.; Offenhäusser, A.; Mourzina, Y. Direct Electrochemistry of Cyt c and Hydrogen Peroxide Biosensing on Oleylamine- and Citrate-Stabilized Gold Nanostructures. Sensors Actuators B 
Chem. 2015, 207, 1045-1052.

(26) Eguílaz, M.; Gutiérrez, A.; Rivas, G. Non-Covalent Functionalization of MultiWalled Carbon Nanotubes with Cytochrome c: Enhanced Direct Electron Transfer and Analytical Applications. Sensors Actuators B Chem. 2016, 225, 74-80.

(27) Yue, H.; Khoshtariya, D.; Waldeck, D. H.; Grochol, J.; Hildebrandt, P.; Murgida, D. H. On the Electron Transfer Mechanism between Cytochrome C and Metal Electrodes. Evidence for Dynamic Control at Short Distances. J.Phys.Chem.B 2006, 110, 19906-19913.

(28) Petrović, J.; Clark, R. A.; Yue, H.; Waldeck, D. H.; Bowden, E. F. Impact of Surface Immobilization and Solution Ionic Strength on the Formal Potential of Immobilized Cytochrome c. Langmuir 2005, 21 (14), 6308-6316.

(29) Murgida, D. H.; Hildebrandt, P.; Wei, J.; He, Y. F.; Liu, H.; Waldeck, D. H. Surface-Enhanced Resonance Raman Spectroscopic and Electrochemical Study of Cytochrome c Bound on Electrodes through Coordination with PyridinylTerminated Self-Assembled Monolayers. J. Phys. Chem. B 2004, 108 (7), 22612269.

(30) Cortina-Puig, M.; Muñoz-Berbel, X.; Calas-Blanchard, C.; Marty, J.-L. Electrochemical Characterization of a Superoxide Biosensor Based on the CoImmobilization of Cytochrome $\mathrm{c}$ and XOD on SAM-Modified Gold Electrodes and Application to Garlic Samples. Talanta 2009, 79 (2), 289-294.

(31) Jin, B.; Wang, G. X.; Millo, D.; Hildebrandt, P.; Xia, X. H. Electric-Field Control of the pH-Dependent Redox Process of Cytochrome $\mathrm{c}$ Immobilized on a Gold Electrode. J. Phys. Chem. C 2012, 116 (24), 13038-13044. 
(32) Wisitruangsakul, N.; Zebger, I.; Ly, K.; Murgida, D. H.; Ekgasit, S.; Hildebrandt, P. Redox-Linked Protein Dynamics of Cytochrome c Probed by Time-Resolved Surface Enhanced Infrared Absorption Spectroscopy. Phys. Chem. Chem. Phys. 2008, 10 (34), 5276-5286.

(33) Zhou, J.; Zheng, J.; Jiang, S. Molecular Simulation Studies of the Orientation and Conformation of Cytochrome c Adsorbed on Self-Assembled Monolayers. J. Phys. Chem. B 2004, 108 (45), 17418-17424.

(34) Nakano, K.; Yoshitake, T.; Yamashita, Y.; Bowden, E. F. Cytochrome c SelfAssembly on Alkanethiol Monolayer Electrodes as Characterized by AFM, IR, QCM, and Direct Electrochemistry. Langmuir 2007, 23 (11), 6270-6275.

(35) Paggi, D. A.; Martín, D. F.; Kranich, A.; Hildebrandt, P.; Martí, M. A.; Murgida, D. H. Computer Simulation and SERR Detection of Cytochrome c Dynamics at SAM-Coated Electrodes. Electrochim. Acta 2009, 54 (22), 4963-4970.

(36) Wei, J.; Liu, H.; Dick, A. R.; Yamamoto, H.; He, Y.; Waldeck, D. H. Direct Wiring of Cytochrome C's Heme Unit to an Electrode: Electrochemical Studies. J. Am. Chem. Soc. 2002, 124 (32), 9591-9599.

(37) Gerard, M.; Chaubey, A.; Malhotra, B. D. Application of Conducting Polymers to Biosensors. Biosens. Bioelectron. 2002, 17 (5), 345-359.

(38) Svirskis, D.; Travas-Sejdic, J.; Rodgers, A.; Garg, S. Electrochemically Controlled Drug Delivery Based on Intrinsically Conducting Polymers. J. Control. Release 2010, $146(1), 6-15$.

(39) Arias-Pardilla, J.; Otero, T. F.; Martínez, J. G.; Ismail, Y. A. Biomimetic Sensing - Actuators Based on Conducting Polymers. In Aspects on Fundaments and 
Applications of Conducting Polymers; Motheo, D. A., Ed.; Intechopen, 2012.

(40) Zhang, L.; Jiang, X.; Niu, L.; Dong, S. Syntheses of Fully Sulfonated Polyaniline Nano-Networks and Its Application to the Direct Electrochemistry of Cytochrome c. Biosens. Bioelectron. 2006, 21 (7), 1107-1115.

(41) Lee, K. P.; Gopalan, A. I.; Komathi, S. Direct Electrochemistry of Cytochrome c and Biosensing for Hydrogen Peroxide on Polyaniline Grafted Multi-Walled Carbon Nanotube Electrode. Sensors Actuators, B Chem. 2009, 141 (2), 518-525.

(42) Dai, Y.; Proshlyakov, D. A.; Swain, G. M. Effects of Film Morphology and Surface Chemistry on the Direct Electrochemistry of Cytochrome $\mathrm{c}$ at Boron-Doped Diamond Electrodes. Electrochim. Acta 2016, 197, 129-138.

(43) Alvin Koh, W. C.; Rahman, M. A.; Choe, E. S.; Lee, D. K.; Shim, Y. B. A Cytochrome c Modified-Conducting Polymer Microelectrode for Monitoring in Vivo Changes in Nitric Oxide. Biosens. Bioelectron. 2008, 23 (9), 1374-1381.

(44) Pandiaraj, M.; Sethy, N. K.; Bhargava, K.; Kameswararao, V.; Karunakaran, C. Designing Label-Free Electrochemical Immunosensors for Cytochrome c Using Nanocomposites Functionalized Screen Printed Electrodes. Biosens. Bioelectron. 2014, 54, 115-121.

(45) Eguílaz, M.; Agüí, L.; Yáñez-Sedeño, P.; Pingarrón, J. M. M. A Biosensor Based on Cytochrome c Immobilization on a Poly-3-Methylthiophene/multi-Walled Carbon Nanotubes Hybrid-Modified Electrode. Application to the Electrochemical Determination of Nitrite. J. Electroanal. Chem. 2010, 644 (1), 30-35.

(46) Kim, H. J.; Lee, K. S.; Won, M. S.; Shim, Y. B. Characterization of ProteinAttached Conducting Polymer Monolayer. Langmuir 2008, 24 (3), 1087-1093. 
(47) Handbook of Conducting Polymers: Conjugated Polymers: Processing and Applications, 4th ed.; Skotheim;, T. A., Reynolds, J. R., Eds.; CRC Press, 2006.

(48) López-Bernabeu, S.; Gamero-Quijano, A.; Huerta, F.; Morallón, E.; Montilla, F. Enhancement of the Direct Electron Transfer to Encapsulated Cytochrome c by Electrochemical Functionalization with a Conducting Polymer. J. Electroanal. Chem. 2017, 793, 34-40.

(49) Bobacka, J.; Lewenstam, A.; Ivaska, A. Electrochemical Impedance Spectroscopy of Oxidized poly(3,4-Ethylenedioxythiophene) Film Electrodes in Aqueous Solutions. J. Electroanal. Chem. 2000, 489 (1-2), 17-27.

(50) Greczynski, G.; Kugler, T.; Salaneck, W. . Characterization of the PEDOT-PSS System by Means of X-Ray and Ultraviolet Photoelectron Spectroscopy. Thin Solid Films 1999, 354 (1), 129-135.

(51) Crispin, X.; F. L. E. Jakobsson; Crispin, A.; Grim, P. C. M.; Andersson, P.; Volodin, A.; Haesendonck, C. van; Auweraer, M. Van der; Salaneck, W. R.; Berggren, M. The Origin of the High Conductivity of Poly(3,4ethylenedioxythiophene)-Poly(styrenesulfonate) (PEDOT-PSS) Plastic Electrodes. Chem. Mater. 2006, 18 (18), 4354-4360.

(52) Gamero-Quijano, A.; Huerta, F.; Salinas-Torres, D.; Morallón, E.; Montilla, F. Electrochemical Behaviour of PSS-Functionalized Silica Films Prepared by Electroassisted Deposition of Sol-Gel Precursors. Electrocatalysis 2014, 33-41.

(53) Mu, C.; Zhao, Q.; Xu, D.; Zhuang, Q.; Shao, Y. Silicon Nanotube Array / Gold Electrode for Direct Electrochemistry of Cytochrome c. J. Phys. Chem. B 2007, $111(6), 1491-1495$. 
(54) Dai, Y.; Proshlyakov, D. A.; Swain, G. M. Effects of Film Morphology and Surface Chemistry on the Direct Electrochemistry of Cytochrome $\mathrm{c}$ at Boron-Doped Diamond Electrodes. Electrochim. Acta 2016, 197, 129-138.

(55) Jiang, X.; Zhang, Z.; Bai, H.; Qu, X.; Jiang, J.; Wang, E.; Dong, S. Effect of Electrode Surface Microstructure on Electron Transfer Induced Conformation Changes in Cytochrome $c$ Monitored by in Situ UV and CD Spectroelectrochemistry. Spectrochim. Acta - Part A Mol. Biomol. Spectrosc. 2005, $61(5), 943-951$.

(56) Gamero-Quijano, A.; Huerta, F.; Morallon, E.; Montilla, F. Modulation of the Silica Sol-Gel Composition for the Promotion of Direct Electron Transfer to Encapsulated Cytochrome c. Langmuir 2014, 30 (34), 10531-10538.

(57) Kvarnström, C.; Neugebauer, H.; Blomquist, S.; Ahonen, H. J.; Kankare, J.; Ivaska, A.; Sariciftci, N. S. In Situ FTIR Spectroelectrochemical Characterization of poly(3,4-Ethylenedioxythiophene) Films. Synth. Met. 1999, 101 (1), 66.

(58) Kvarnström, C.; Neugebauer, H.; Ivaska, A.; Sariciftci, N. S. Vibrational Signatures of Electrochemical P-and N-Doping of Poly (3, 4Ethylenedioxythiophene) Films: An in Situ Attenuated Total Reflection Fourier Transform Infrared. J. Mol. Struct. 2000, 521, 271.

(59) Damlin, P.; Kvarnstrom, C.; Ivaska, A. Electrochemical Synthesis and in Situ Spectroelectrochemical Characterization of poly(3,4-Ethylenedioxythiophene) (PEDOT) in Room Temperature Ionic Liouids. J. Electroanal. Chem. 2004, 570 (1), 113-122.

(60) Łapkowski, M.; Proń, A. Electrochemical Oxidation of poly(3,4Ethylenedioxythiophene) _ “in Situ” Conductivity and Spectroscopic 
Investigations. Synth. Met. 2000, 110 (1), 79-83.

(61) Louarn, G.; Kruszka, J.; Lefrant, S.; Zagorska, M.; Kulszewicz-Bayer, I.; Proń, A. Spectroscopic Properties of poly(3-Alkylthiophenes) and Their "head-to-Head", “tail-to-Tail” Coupled Analogues poly(4,4'-Dialkyl-2,2'-Bithiophenes). Synth. Met. 1993, 61 (3), 233-238.

(62) Hernandez, V.; Ramirez, F. J.; Otero, T. F.; Lopez Navarrete, J. T. An Interpretation of the Vibrational Spectra of Insulating and Electrically Conducting poly(3-Methylthiophene) Aided by a Theoretical Dynamical Model. J. Chem. Phys. 1994, 100 (1), 114-129.

(63) Garreau, S.; Duvail, J. L.; Louarn, G. Spectroelectrochemical Studies of Poly (3,4Ethylenedioxythiophene) in Aqueous Medium. Synth. Met. 2002, 125, 325-329.

(64) Garreau, S.; G. Louarn; J. P. Buisson; Froyer, G.; Lefrant, S. In Situ Spectroelectrochemical Raman Studies of Poly(3,4-Ethylenedioxythiophene) (PEDT). Macromolecules 1999, 32 (20), 6807-6812.

(65) Mayo, D. W. Characteristic Frequencies of Aromatic Compounds (Group Frequencies of Arenes). In Course Notes on the Interpretation of Infrared and Raman Spectra; John Wiley \& Sons, Inc.: Hoboken, NJ, USA, 2004; pp 101-140.

(66) Garreau, S.; Duvail, J. L.; Louarn, G. Spectroelectrochemical Studies of poly(3,4Ethylenedioxythiophene) in Aqueous Medium. Synth. Met. 2001, 125 (3), 325329.

(67) Pons, S.; Korzeniewski, C.; Shirts, R. B.; Bewicks, A. Field-Induced Infrared Absorption in Metal Surface Spectroscopy: The Electrochemical Stark Effect. $J$. Phys. Chem. 1985, 89 (11), 2297-2298. 
(68) Szkurlat, A.; Palys, B.; Mieczkowski, J.; Skompska, M. Electrosynthesis and Spectroelectrochemical Characterization of poly(3,4-Dimethoxy-Thiophene), poly(3,4-Dipropyloxythiophene) and poly(3,4-Dioctyloxythiophene) Films. Electrochim. Acta 2003, 48 (24), 3665-3676.

(69) Jones, C. L.; Higgins, J.; Christensen, P. A.; Higgins, S. J.; Higgins, J.; Christensen, P. A. Some in Situ Reflectance Fourier Transform Infrared Studies of Electrochemically Prepared Polybenzo[c]thiophene and Poly-5Fluorobenzo[c]thiophene Films. J. Mater. Chem. 2002, 12 (3), 758-764.

(70) Cravino, A.; Neugebauer, H.; Petr, A.; Skabara, P. J.; Spencer, H. J.; Mcdouall, J. J. W.; Dunsch, L.; Sariciftci, N. S. Spectroelectrochemistry of Poly ( Ethylenedithiathiophene ) - the Sulfur Analogue of Poly ( Ethylenedioxythiophene ). J. Phys. Chem. B 2006, 110 (6), 2662-2667.

(71) Schlereth, D. D.; Maentele, W.; Mäntele, W. Electrochemically Induced Conformational Changes in Cytochrome c Monitored by Fourier Transform Infrared Difference Spectroscopy: Influence of Temperature, $\mathrm{pH}$, and Electrode Surfaces. Biochemistry 1993, 32 (4), 1118-1126.

(72) Ataka, K.; Heberle, J. Functional Vibrational Spectroscopy of a Cytochrome c Monolayer: SEIDAS Probes the Interaction with Different Surface-Modified Electrodes. J. Am. Chem. Soc. 2004, 126 (30), 9445-9457.

(73) Barth, A. Infrared Spectroscopy of Proteins. Biochim. Biophys. Acta - Bioenerg. 2007, 1767 (9), 1073-1101.

(74) Dong, A.; Huang, P.; Caughey, W. S. Protein Secondary Structures in Water from Second-Derivative Amide I Infrared Spectra. Biochemistry 1990, 29 (13), 33033308. 
(75) Speare, J. O.; Rush, T. S. IR Spectra of Cytochrome c Denatured with Deuterated Guanidine Hydrochloride Show Increase in Beta Sheet. Biopolym. Biospectroscopy Sect. 2003, 72 (3), 193-204.

(76) Kaiser, A. B. Thermoelectric-Power and Conductivity of Heterogeneous Conducting Polymers. Phys. Rev. B 1989, 40 (5), 2806-2813.

(77) Lin, S.; Jiang, X.; Wang, L.; Li, G.; Guo, L. Adsorption Orientation of Horse Heart Cytochrome c on a Bare Gold Electrode Hampers Its Electron Transfer. J. Phys. Chem. C 2012, $116(1), 637-642$.

(78) Miteva, M. A.; Kossekova, G. P.; Villoutreix, B. O.; Atanasov, B. P. Local Electrostatic Potentials in Pyridoxal Phosphate Labelled Horse Heart Cytochrome c. J. Photochem. Photobiol. B Biol. 1997, 37 (1-2), 74-83.

(79) Breuker, K. Segmental Charge Distributions of Cytochrome c on Transfer into the Gas Phase. Int. J. Mass Spectrom. 2006, 253 (3), 249-255. 
TOC graphic

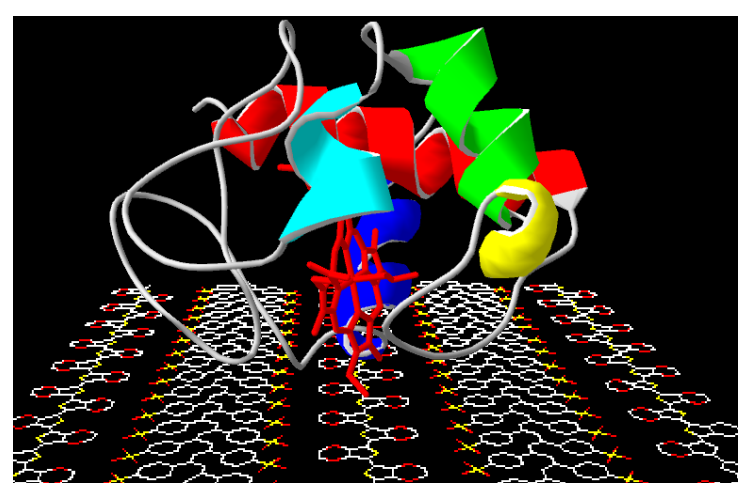

